\title{
Cost Optimization on Energy Consumption of Punching Machine Based on Green Manufacturing Method at PT Buana Intan Gemilang
}

\author{
Ayudia Prillia ${ }^{1}$, Haris Rachmat ${ }^{1}$, and Tatang Mulyana ${ }^{1}$ \\ ${ }^{1}$ School of Industrial Engineering Telkom University, Bandung, Indonesia.
}

\begin{abstract}
PT Buana Intan Gemilang is a company engaged in textile industry. The curtain textile production need punching machine to control the fabric process. The operator still works manually so it takes high cost of electrical energy consumption. So to solve the problem can implement green manufacturing on punching machine. The method include firstly to identify the color by classifying the company into the black, brown, gray or green color categories using questionnaire. Secondly is improvement area to be optimized and analyzed. Improvement plan at this stage that is focusing on energy area and technology. Thirdly is process applies by modifying the technology through implementing automation system on the punching machine so that there is an increase of green level on the process machine. The result obtained after implement the method can save cost on electrical energy consumption in the amount of Rp 1.068.159/day.
\end{abstract}

\section{Introduction}

In this era with the development of technology and increasing in population, energy as one of resources that will always be needed for the whole societies especially electrical energy. With the rapid development of technology, informatiom, and industrial, there are problems for energy limitations. Fossil energy resources continuously vanished as it is a producer of electrical energy and fuel oil, it is necessary to find ways in order to save electric energy use and fuel oil so it would not wasting energy. From the data of national electricity power sales, the industrial sector is the largest user of electric energy. The use of technology in the industry will be continusly developed because the industry has to fullfill the costumer's needs, so the industry will need more energy for supply process. Studies of energy efficiency in machining process have been carried out from many aspects.

According to the research levels and techniques used in energy-reducing strategies, these efforts can be classified into three groups: approaches by improving functions of machine tools or selecting alternative machine tools for specific tasks; approaches by optimizing machining conditions like cutting parameters, cutter's material, etc and approaches by

*Corresponding author: ${ }^{1}$ ayudiaprilliaa@gmail.com 
reconfiguring machining systems. Improvement plan in terms will focus about consumption electricity energy in punching machine [1]. Implementation along with technology modifications automation so will generate efficiency cost savings. Green manufacturing is a sustainable approach to the design and engineering activities involved in product development and/or system operation to minimize environtmental impact [2]. The method of Green Manufacturing can efficiently be used by technology and save energy consumption on the industry. Implementation along with technology modifications automation so will generate efficiency cost savings. Automation technology is widely used for controlling the production process or the process of working punching machine and monitoring consumption energy. The use of designing automation technologies applied by the company to facilitate, user friendly, and also important because the system automation can reduce the impact of human error.

\section{Basic theory}

\subsection{Punching Machine Process}

A punching mechanism is designed to cut a hole in some material such as paper, metal, or as in IBM machines, card stock. The original loom was first called a "treadle loom", later as "pattern loom" and finally a "draw loom". Now, Jacquard machine has developed into an electronic form with computer controlling, and Net communication is widely used in jacquard weaving sheds. Meanwhile, the number of hooks used in the electronic Jacquard machine has increased to 20,000 [3]. Punching process is designed to cut a hole in some material such as paper, metal, or card stock. There are three basic elements of punching device, a punch, a die, and a stripper. The punch is the piece which is driven through the card and cuts the hole. The die serves as a base, supports the card while it is being cut. The stripper serves as a guide for the punch and as a means of stripping the card from the punch after the latter has cut the card. Fig 1 show punching process the components consist of workpiece, die, scrap, clearance and punch.

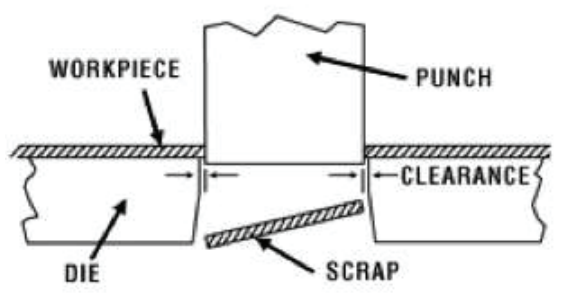

Fig.1. Punching Machine Process

\subsection{Green Manufacturing}

Green manufacturing is a method for manufacturing that minimizes waste and pollution. These goals are often achieved through product and process design [4]. Green manufacturing should be viewed as an opportunity to expand the local and global market share in this dynamic environment. A deeper understanding of green manufacturing strategies and techniques will enable manufacturers to realize that unlike other competing manufacturing strategies (like cost and time), being green positively impact all other manufacturing competitive edges. For example reducing material wastes and energy consumption will 
reduce production cost and improve production time. Going green in manufacturing will also improve the quality of the production process which will in turn impact product quality and also will be more appealing to the growing number of customers looking for green manufacturers and products, Fig 2 show aspect manufacturing strategy.

Fig.2. Manufacturing strategies [2]

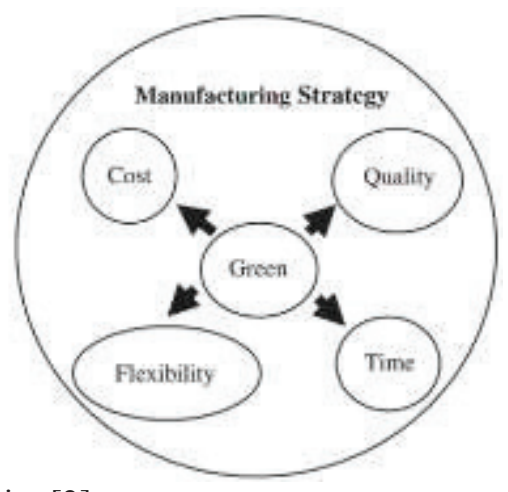

Energy matter in green manufacturing not only because of economic costs added to the products but also because of environmental impacts associated with the energy production and supply [5]. Green manufacturing is a sustainable approach to the design and engineering activities involved in product development and/or system operation to minimize environmental impact. Fig 3 explain system model architecture for the design and control of the green manufacturing systems. The architecture is composed of two modules; the first module describes the design and planning processes of the green manufacturing systems and the second module describes the control process that controls the design and planning process at each level.

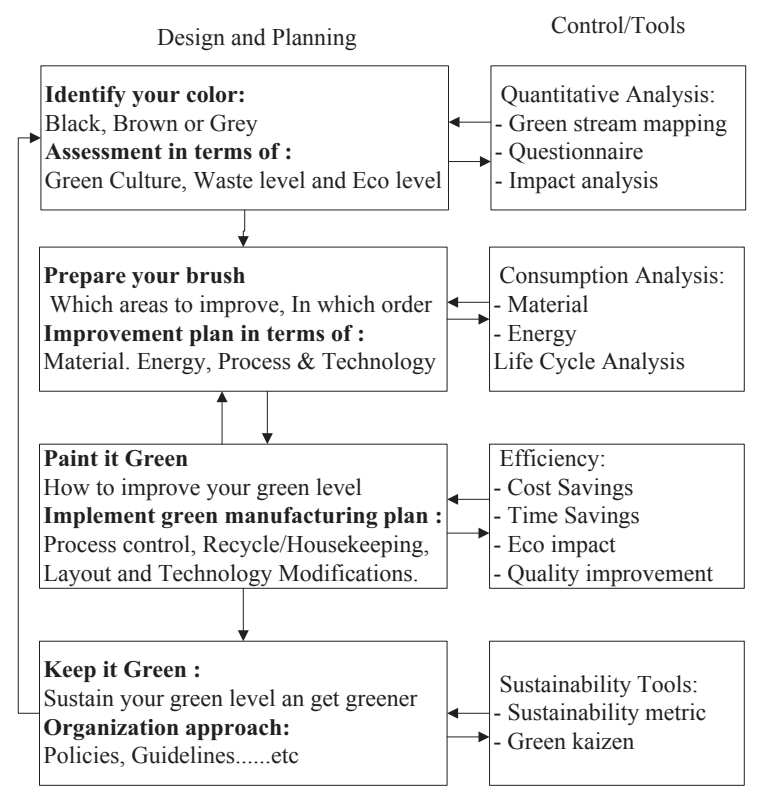

Fig.3. System model for green manufacturing [2] 


\subsection{Automation Components}

Automation consists of three basic elements, actuator, controller, and sensor. The actuator which does the work, and controlled by the controller. The actuator in an automated process may in fact be several actuators, each of which provides an output that drives another in the series of actuator. The controller which tells the actuator to do work may be a simple digital system or an analog system. The sensor is provides feedback to the controller so that it knows the actuator is doing work which. These three elements have been integrated into a mechanical system either electronic, and computer-based systems to operate and control the production [6]. Fig 4 show elements of automated system consist of power, program of instructions, control system, process, and ouput.

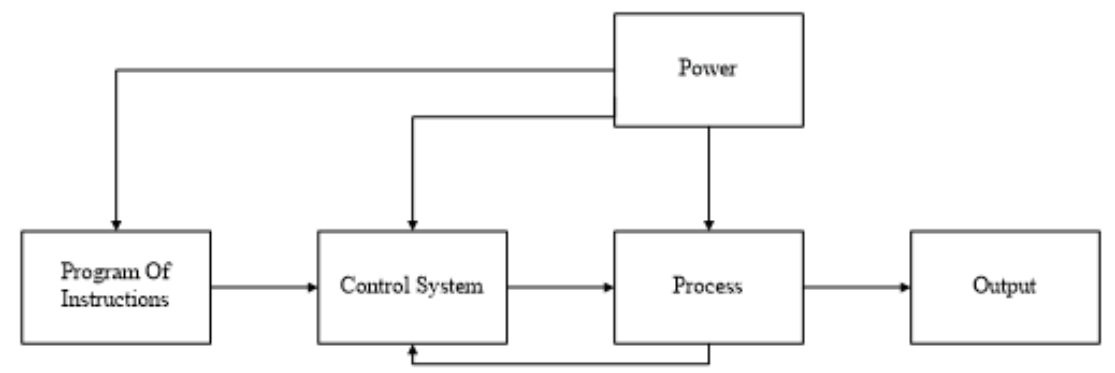

Fig.4. Elements of Automated System [6]

For the example control system is SCADA, that computer based that are used to controlling a process such as industrial processes on manufacturing, production and power generator [7]. SCADA integrated with PLC, based on [8] PLC use software program of Totally Integrated Automation. System monitoring would be done by utilizing the Human Machine Interface (HMI) that will be created by using Wonderware In touch 10.0. In the design of this system required a computer with Windows XP SP3. It also required software for the design of the Wonderware In touch 10.0, Active Factory 9.2, Active X Wonderware Generic Data Grid, Wonderware, SQL Server 2005 I/O Server DASSI direct, and Totally Integrated Automation (TIA). All hardware that is used as a conduit transmission needs between devices. UTP cable required with RJ 45 for liaison between switches with the server computer, the client computer and PLC. Sensors and actuators connected to a PLC by using cables.

\section{Results and discussion}

\subsection{Description}

The products of curtain and curtain fabric have various patterns that will make the motif more beautiful. To create some patterns that varies on the weaving machine required jacquard card so it can form the desired pattern. One type of fabric pattern is required to produce as many as 2500 pattern cards and for the pattern of curtains required the production of pattern cards as much as 600 . The specification of jacquard cards have a width of $6,5 \mathrm{~cm}$ and length of $62,5 \mathrm{~cm}$. The jacquard product consists of three parts that have its own hole patterns. Each part has a header with a big hole and 2 other holes on the next row. Below the header, there are 12 columns and 33 rows. Each hole of all parts has diameter of 0,45 while the big hole size on the header is 0,7 . Jacquard Punching machine to produce jacquard card has several main components show Fig 5. 

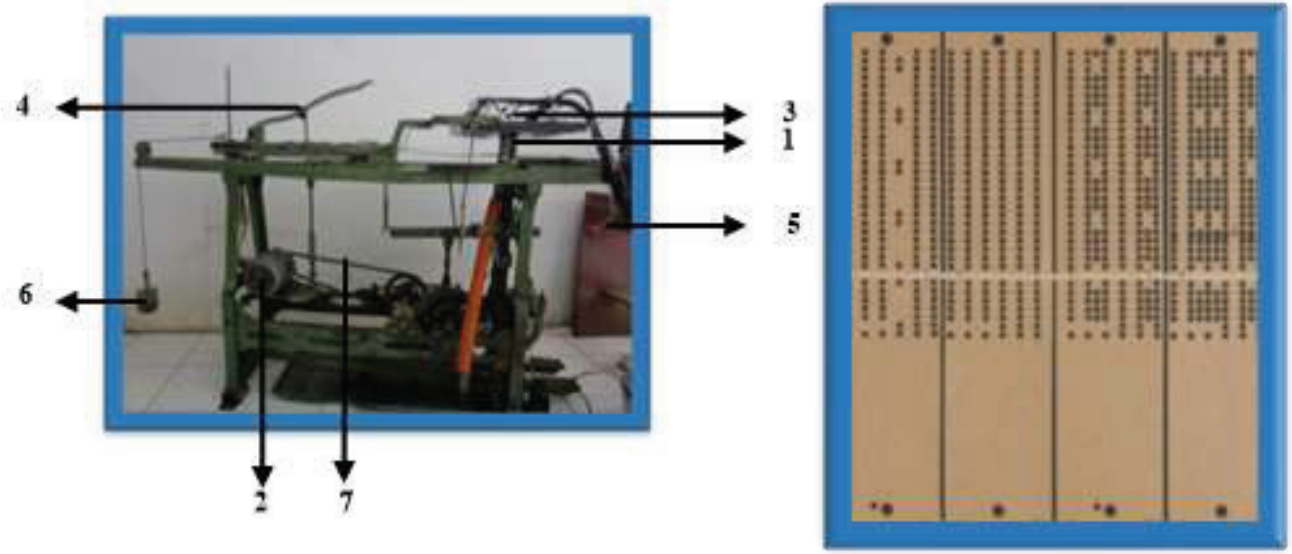

Fig.5. Jacquard Card \& Punching Machine

Component number on punching machine
1. Drill
5. Lower Handle
2. AC Motor
6. Pendulumdur
3. 12 Solenoid
7. Belt
4. Upper Handle

\subsection{Green manufacturing}

\section{Identify Color}

To apply the method of green manufacturing in a company, the first step is to identify the color or culture on the company and the results is still not optimized. Quantitative analysis control tools is performed to measure the color of the company into the category of black, brown, gray, or green. If the results obtained by the company are green and still included in the black ,brown and gray then the green manufacturing method needs to be applied thus the improvement in getting the company reduces waste in the form of energy, material, process and technology. Thus it can be proceeded into the next stage. Fig 6 show model for the assessment layer to identify color.

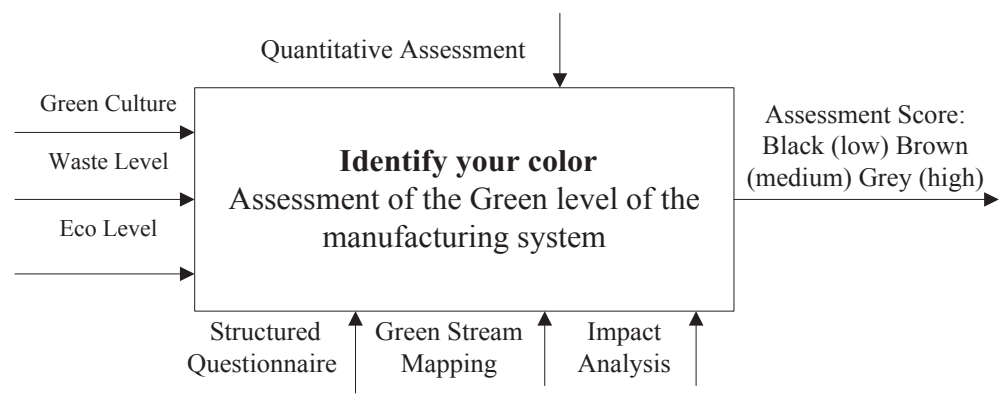

Fig.6. Model for the Assessment Layer [2]

Some tools that can be used in identifying companies with quantitative analysis are green stream mapping, questionnaire, and impact analysis tools. The control tool used to identify 
corporate colors in this study is uses questionnaires distributed to operators who operate jacquard punching machines, in order to classify companies into certain category. These are examples of forms of questions classified as focus into the use of energy and materials :

1. Can the rest of production process result be used again to become raw materials?

2. Is there any technology that can generate its own electricity? Such as solar panels, water turbines or windmills?

Table 1. Results of Weighted Questionnaires

\begin{tabular}{|c|c|c|c|}
\hline Rank & Object & Weight & Persentage \\
\hline 1 & Material & 2,13333 & $41 \%$ \\
\hline 2 & Energy & 3,125 & $59 \%$ \\
\hline \multicolumn{2}{|c|}{ Total } & 5,25833 & $100 \%$ \\
\hline
\end{tabular}

Questionnaires were given to 5 operators of PT Buana Intan Gemilang. After calculating recapitulation process based on questionnaires, the results obtained are percentage of materials as much as $41 \%$ and Energy of $59 \%$ in accordance to Table IV Results of Weighted Questionnaires. Based on the materials and energy percentage results, the company's category included in the category of score brown (medium).

2. Prepare your brush

After identifying the color of the company with the brown result (medium) it is necessary to impelement green manufacturing method so that the increasing color becomes better and can reduce the waste in energy, material, process and technology. This stage of the plan is to determine the objects will be analyzed to eliminate waste and optimization occurs in terms of costs incurred by the company. From the results of questionnaires distribution of energy needs in the company process is very influential. Thus, in this process of the object plan will study about energy, in the form of electrical energy used by companies, especially in the punching machine with the change of energy consumption and technological improvement, it is expected that green manufacturing can be implemented. Fig 7 show stage for model for green improvement/implementation planning layer.

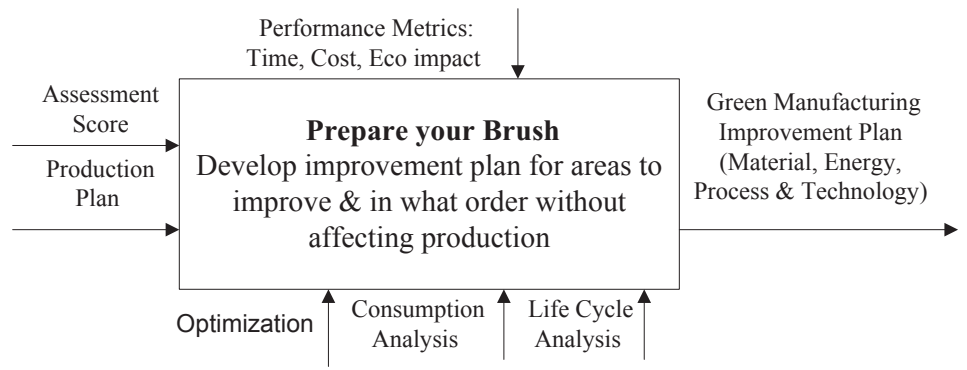

Fig.7. Model for Green Improvement/Implementation Planning layer[2]

\section{Paint it Green}

In the previous process (prepared your brush) has been determined that the use of energy and technological improvement is an object plan that will be analyzed according to the punching machine process. 


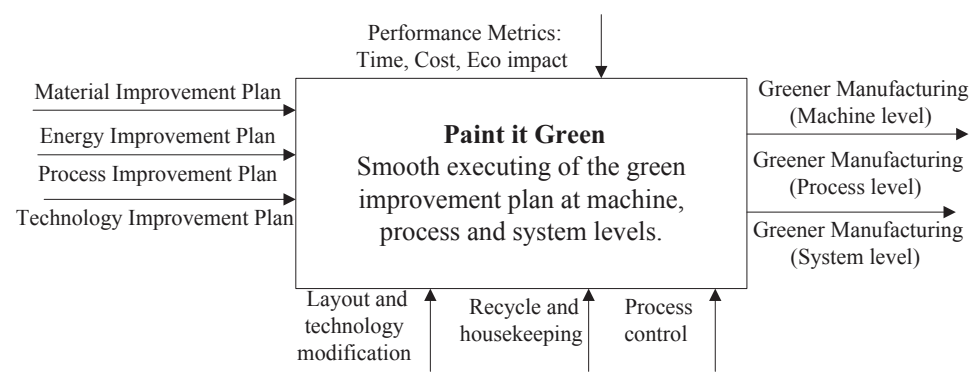

Fig.8. Model for Green Manufacturing Plan Implementation Layer [2]

The process that is done this time is paint it green if improvement plan on machine process punching machine has been done. With the modification of technology on the process machine by implementing the automation system is expected to reduce waste energy use and can perform optimization in terms of costs on the use of electrical energy. The following framework on the automation system punching machine can be seen in Fig 9.

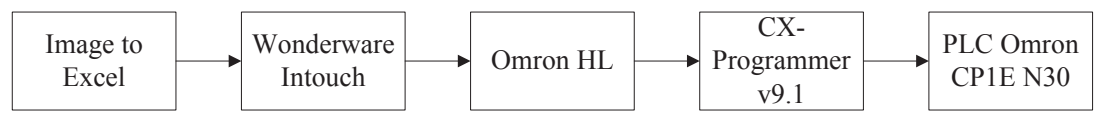

Fig.9. Framework Automation System

\subsection{Automation System}

\section{Image to Excel}

This software used to convert pattern image .bmp became binary data. After the pattern image became binary data, a row of binary data on microsoft excel automated calculated to Hexadecimal, then Hexadecimal data will be upload at Wonderware InTouch so PLC script can running it. Fig 10 show display microsoft excel 2007 image converter.

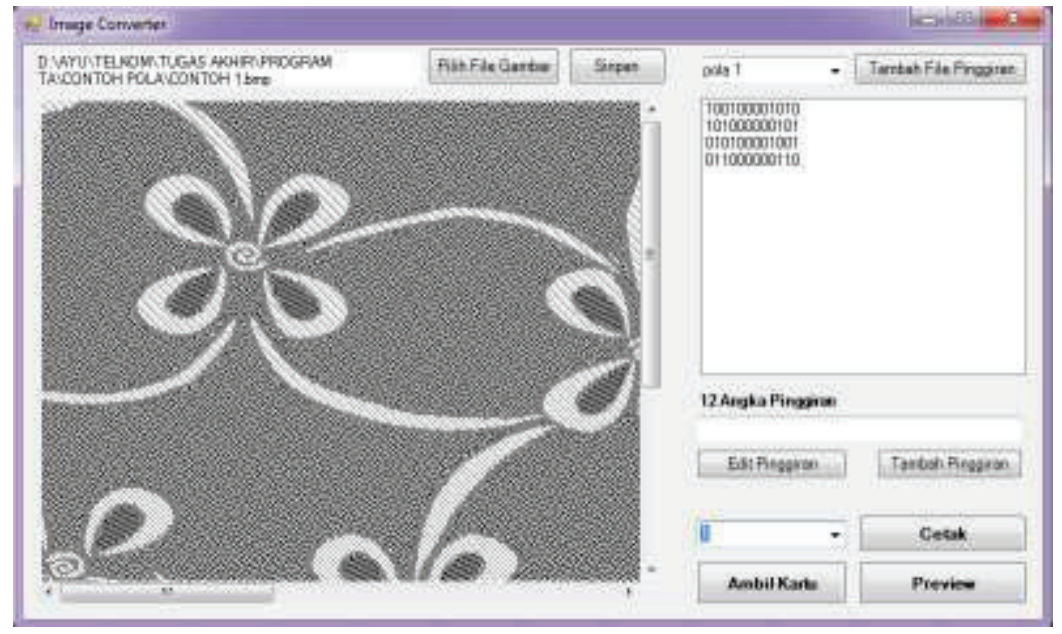

Fig.10. Microsoft Excel 2007 Image converter 
2. Wonderware Intouch

a. Login window

The login page is the initial view when opening the HMI system. This login system is a security system provided only to workers who do have responsibility for operating a punching machine. On this page is required to fill the User ID and Password to be able to access other pages.

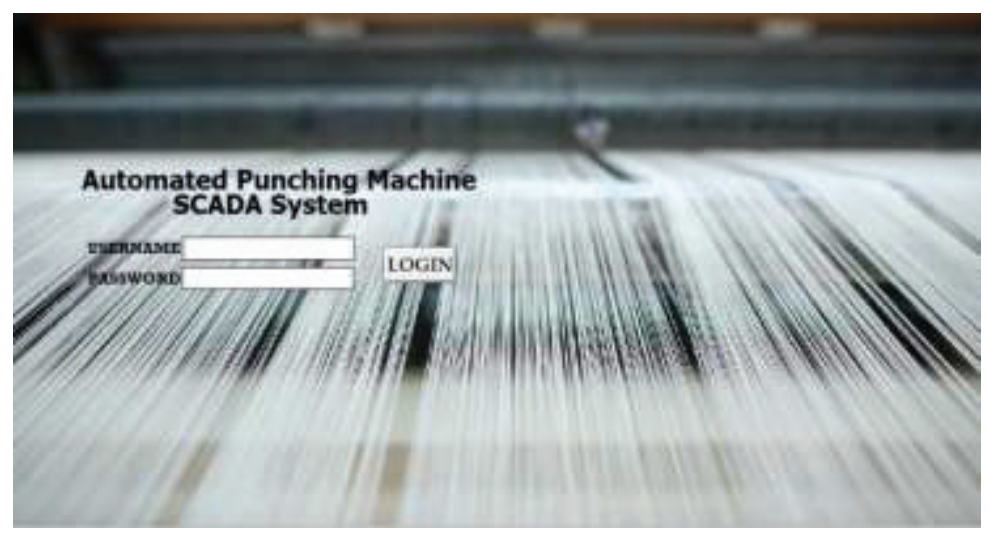

Fig.11. Log In window HMI

b. Main window

This window is a window that displays the result of hexadecimal number obtained from convert pattern in Microsoft Excel to be given to CX-Programmer. To create a whole pattern card there are 3 parts on the jacquard card. 1 part consists of 33 rows.

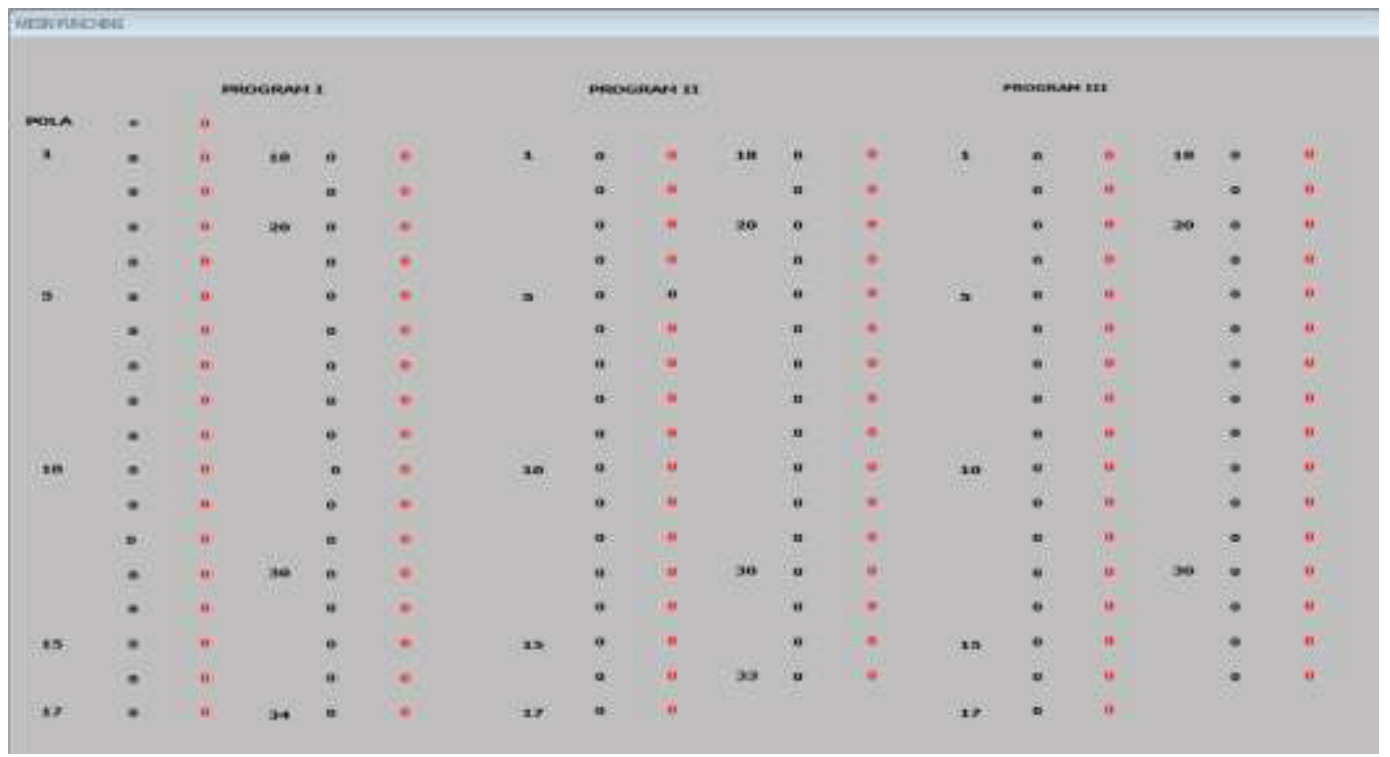

Fig.12. Main Window HMI 
3. PLC Programming

1. Section General Process

a. Strating process

This process to start the program as a whole. To enable the Start input and will be active if the $15 \mathrm{~s}$ TM seconds timer, timer function to delay the process and provide a time delay when Wonderware InTouch uploads the hexa code input for CXProgrammer. Once the TM timer is active and the start input is also active, then Run ouput will also be active.

b. Create header process

After the input Run active, then the process starts with the creation of the header on the jacquard card. The header on the first row that is marked with 2 holes 3 TICK and TICK 10 made by solenoid solenoid 3 and 10. To activate the output solenoid 3 and 10, the input of must be enabled. After the output is active then the next timer TM 001 will be active for 2 seconds to give time lag enable MAIN VALVE on the creation of a hole in the middle is a large header card.

c. Run Bagian 1

The next process this time is a ladder that will give an instruction to jaquard making process. A shift register is a function that activates internal relay. Internal relay is an input for each row which will activate the solenoid valve according to the hex rate of HMI. Run program part one is a program to create pattern on 33 first row on pattern card.

d. Spasi Bagian 1

After the program instructs to activate the solenoid, this script is to instruct the spacebar so that the next solenoid will create hole on the next row.

2. Bagian 1

This section is part of the MOV data transfer input process of the Wonderware InTouch hexadecimal, there are 35 steps or 35 rows in the jacquard card hole making section 1. There are input until STEP 35, Output MOV for STEP 1. This process of recording data from Hexadecimal code input from Wonderware InTouch.

3. Output Bagian 1

After the Hexadecimal code record process of the InTouch wonderware is stored according to the above process, then this process executes the solenoid which will create a hole in the jacquard card on the 1 st part. There are 12 solenoid that will make a hole in the jacquarq card.

4. Output PLC

This section is a solenoid command that moves according to the section. Existing internal relays that have been previously described. This script program will run solenoid valve 1 until selenoid valve 12 . These solenoid valves are the output to move solenoid one to solenoid valve 12 . Solenoid will move simultaneously while each executes The step or row based on input hexa number.

5. End

On any program CX-Programmer should end with an end script. The function of the end is to close the program that has been created in one program. 


\subsection{Calculating Energy Consumption}

Energy consumption on AC Motor punching machine, to calculate energy consumption need data AC motor is shown in Tabel 2.

Table 2. Data AC Motor

\begin{tabular}{|c|l|l|l|l|l|}
\hline Name Motor & $\mathrm{P}(\mathrm{kW})$ & $\mathrm{V}(\mathrm{v})$ & $\mathrm{I}(\mathrm{A})$ & \multicolumn{2}{|c|}{} \\
\hline \multirow{5}{*}{$\begin{array}{c}\text { Motorcycle pump } \\
\text { ZD1200627 }\end{array}$} & 55 & 380 & 134,2 & \multicolumn{2}{|c}{} \\
\cline { 2 - 4 } & $\mathrm{Fasa}$ & $\mathrm{V}(\mathrm{i}-\mathrm{i})$ & $\mathrm{I}(\mathrm{A})$ & $\operatorname{Cos} \phi$ & $\mu$ \\
\cline { 2 - 4 } & $\mathrm{R}$ & 387 & 112 & & \\
\cline { 2 - 4 } & $\mathrm{S}$ & 385 & 118 & \multirow{2}{*}{0,86} & \multirow{2}{*}{0,95} \\
\cline { 2 - 4 } & $\mathrm{T}$ & 385 & 113 & & \\
\hline
\end{tabular}

Based on [9] by calculating the load as the ratio between input power (measured by power analysis tool) and power value at $100 \%$ loading. For a three phase motor, the step is to determine the input power is given in equation (1)

$$
\mathrm{Pi}=\frac{\mathrm{V} \times \mathrm{I} \times \operatorname{Cos} \phi \times \sqrt{3}}{1000} k w h
$$

$\mathrm{Pi}=$ three phase power $(\mathrm{kW})$

$\mathrm{V}=\operatorname{current}(\mathrm{V})$

$\mathrm{I}=$ current $(\mathrm{A})$

$$
\mathrm{Pi}=\frac{385,67 \times \mathrm{I} 14 \times \operatorname{Cos} 0,86 \times \sqrt{3}}{1000} k w h=49,7993
$$

Determine the value of incoming power at full load, is given in equation (2)

$$
\operatorname{Pr}=\frac{\mathrm{P}}{\eta_{r}} k w
$$

$\mathrm{Pr}=$ incoming power at full load $(\mathrm{kW})$

$\mathrm{P}=$ power $(\mathrm{kW})$

$\eta_{r}=$ efficiency is full load

$$
\operatorname{Pr}=\frac{75}{0,95} k w h=78,9474 k w h
$$

Then calculate the load in $\%$ is given in equation (3)

Where:

$$
\text { Load }=\frac{P i}{P_{r}} \times 100 \%
$$

Load $=$ Output expressed in $\%$ nominal power value

Load $=49,7993 / 78,9474 \times 100 \%=63 \%$

Based on [10] After measuring the current and voltage, and calculating the power consumption of motor and then it can be calculated estimation of electrical energy consumption for each motor. It got enter power (Pi) and motor operation period every day is for 7 hours, then estimation of daily electrical energy consumptio is given in equation (4). 


$$
\mathrm{W}=\mathrm{P} \times \mathrm{t}
$$

Where:

$\mathrm{W}=$ Changes in electrical energy $(\mathrm{kWh})$

$\mathrm{P}=$ power used $(\mathrm{kW})$

$\mathrm{T}=$ time interval $(\mathrm{hr})$

Motor Load $=75 \mathrm{~kW}$ x $63 \%=47.3093$

$\mathrm{W}=\mathrm{P} \times \mathrm{t}$

$=49.7993 \times 7$ hours

$=348,5950096 \mathrm{kWh}$ Energy consumption for 1 business day

Reduction of processing time would increase production capacity so that the reduce consumption energy. The following is a calculation of consumption energy in one year :

Known :

- Working time per shift $=7$ hours $\times 3600=25200$ seconds

- Cost for energy electricity $=\mathrm{Rp} 1.035,78 \mathrm{Rp} / \mathrm{kWh}$

- Energy (W) = 348,6 kWh

- Cost Energy per day = Rp 361.068

To get the costs incurred by the use of the machine punching can be calculated with the equation below, based on the energy use and energy costs listrik/kWh.

Cost Saving $=\mathrm{kWh} /$ tahun $\times \mathrm{Rp} / \mathrm{kWh}$

Tabel 3. Data Result Energy Consumption

\begin{tabular}{|l|r|r|}
\hline & \multicolumn{1}{|c|}{$\begin{array}{c}\text { Production Machine } \\
\text { Punching Before In } \\
\text { Automation }\end{array}$} & $\begin{array}{c}\text { Production Machine } \\
\text { Punching After In } \\
\text { automation }\end{array}$ \\
\hline $\begin{array}{l}\text { Total Card Pattern } \\
\text { Required }\end{array}$ & 7200 & 7200 \\
\hline Production time to create & 323 & 84 \\
\hline Time per day / second & 25200 & 25200 \\
\hline Production Results/day & 76 & 300 \\
\hline Total Days needed & 95 & 24 \\
\hline $\begin{array}{l}\text { Total Energy required } \\
\text { kWh }\end{array}$ & 33116,52591 & 8366,28023 \\
\hline Total costs incurred & Rp34.301.435 & Rp8.665.626 \\
\hline
\end{tabular}

\section{Conclusion}

Based on theresearch that had been conducted by implementing design green manufacturing method and automation system design on the punching machine, it can conclude as follows:

1. Has done identification the color at the company, and determine improvment area energy and automation system on the punching machine using Image Converter Microsoft Office 2007, CX Programmer v9.1, PLC Omron CP1E, and Wonderware Intouch was implemented at punching machine.

2. Automated system increased production jacquard card, it can produce 300 jacquard card in one day, previously it only produced 77 jacquard card/day. Then to produce 12 patterns, energy consumption of automated punching machines is $8.366 \mathrm{kwh}$, previously spent $33.116 \mathrm{kwh}$. So the cost to use of electrical energy consumption to 
produce 12 patterns on an automated punching machine can save the cost Rp 1.068 .159 / day

\section{References}

[1] Yingjie, Z. (2014). Energy efficiency techniques in machining process: a review.

[2] Deif, A. M. (2011). A system model for green manufacturing. Journal of Cleaner Production .

[3] Frankie M.C, NG (2006). Digital Jacquard Textile Design In A Colorless Mode Hongkong: Universitas Hongkong

[4] Foster, S. T. (2003). Managing quality : an integrative approach . London: Upper Saddle River.

[5] Dornfeld, D. A. (2013). Green Manufacturing Fundamentals and Applications. California : Springer.

[6] Groover, M. P. (2001). Otomasi, Sistem Produksi, dan Computer-Integrated Manufacturing. New Jersey: Pearson.

[7] Deshpande, V. S. 2014, Home Automation Using PLC and SCADA, Multidisciplinary Journal of Research in Engineering and Technology, Volume 1, Issue 1 (April 2014), 111-118

[8] Rachmat H. Andias Anugrah, Rino. Mulyana Tatang (2015). EMS-SCADA Design Of Ac Usage On A Building: Proceeding 8th International Seminar on Industrial Engineering and Management. ISSN : 1978-774X

[9] Agung, Raharjo, B (2014) Studi Analisis Konsumsi dan Penghematan Energi di PT. P.G. Krebet Baru I. Malang: Universitas Brawijaya

[10] Shantia, K, (2014) Analisis Pemanfaatan Energi Listrik pada Mesin-mesin Produksi Divisi Pabrikasi Di PT INKA Madiun. Malang: Universitas Brawijaya 